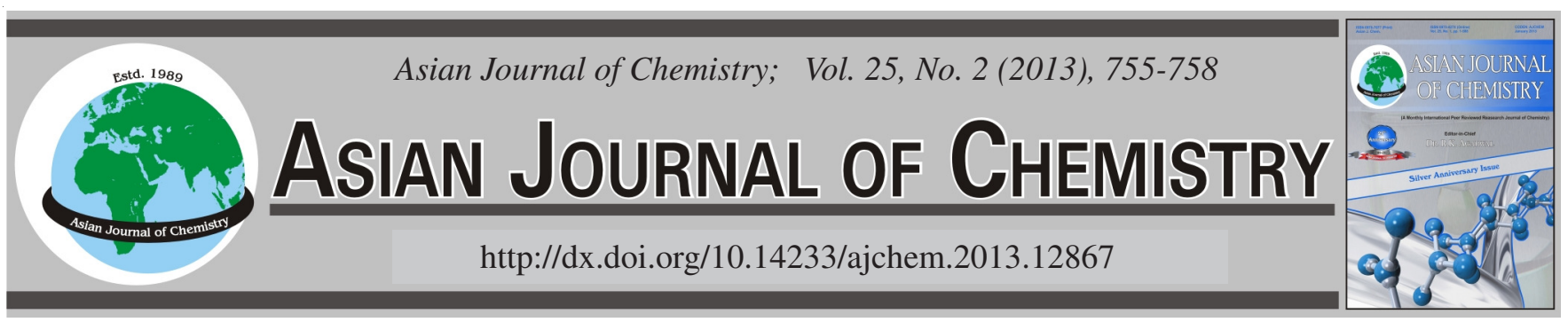

\title{
Photodegradation of Malachite Green by Immobilization of Titanium Dioxide on Glass Plates
}

\author{
Pei-Wen LeE ${ }^{1}$, Siew-Teng Ong ${ }^{1, *}$, Yung-Tse Hung $^{2}$ and Siew-Ling LeE ${ }^{3}$
}

${ }^{1}$ Department of Chemical Science, Faculty of Science, Universiti Tunku Abdul Rahman, Jalan Universiti, Bandar Barat, 31900 Kampar, Perak, Malaysia

${ }^{2}$ Department of Civil and Environmental Engineering, Cleveland State University, Cleveland, Ohio, U.S.A.

${ }^{3}$ Ibnu Sina Institute for Fundamental Science Studies, Universiti Teknologi Malaysia, 81310 UTM Skudai, Johor, Malaysia

*Corresponding author: Fax: +60 5 4661676; E-mail: ongst@utar.edu.my; ongst_utar@yahoo.com

\begin{abstract}
The effects of $\mathrm{pH}$, contact time, initial dye concentration, numbers of dip coating, light sources and repetitive usage of dip-coated $\mathrm{TiO}_{2}$ | were studied in batch experiments in order to investigate the photodegradation efficiency of malachite green in aqueous solution by using titanium dioxide, $\mathrm{TiO}_{2}$ immobilized on glass plates. The photodegradation of malachite green was found to be more effective at lower initial dye concentration. Kinetic studies showed good correlation coefficient for a pseudo-first order kinetic model. The removal of malachite green was dependent on the $\mathrm{TiO}_{2}$ loading where the percentage removal of malachite green was $92.15,94.28$ and $98.43 \%$ for 5, 10 and 15 number of $\mathrm{TiO}_{2}$ dip-coating, respectively. Among the three light sources used, sunlight possessed the highest removal efficiency with $100 \%$ of removal of dye in $6 \mathrm{~h}$ of irradiation. The degradation of malachite green was enhanced in basic solution compared with acidic solution due to the amphoteric property of $\mathrm{TiO}_{2}$. The decolourization efficiency was found to be decreased after each repetitive usage of dip-coated $\mathrm{TiO}_{2}$ glass plates. However, the immobilized $\mathrm{TiO}_{2}$ still displayed a good performance in the removal of malachite green.
\end{abstract}

Key Words: Malachite green, Photodegradation, $\mathrm{TiO}_{2}$, Batch experiments, Decolorization efficiency.

\section{INTRODUCTION}

Large quantities of dyes are extensively used in the fundamental processing steps of textile industries. It is estimated that about $15 \%$ of the total world production of dyes is lost during the dyeing and finishing operations and is released in the wastewater ${ }^{1,2}$. Thus, these dyes released into the environment without treatment will cause severe ecological problems to the nature. Nevertheless, increased public concerns about these compounds and the stringent international environment standards (ISO 14001) have promoted the need to develop novel treatment methods for converting these organic dyes to harmless compounds ${ }^{3}$. Thus, attention has been focused on treating the effluents before discharging into environment.

The conventional treatment methods for colour removal from industrial effluents are divided into three categories i.e., physical, biological and chemical. Biological treatment uses bacteria or microorganisms to decompose the waste while chemical treatments involve the addition of oxidizing or reducing agents, coagulants and other chemicals. Chemical treatments involve the usage of chemicals and although the dyes are removed, the accumulation of concentrated sludge creates a disposal problem. As for physical treatment methods, this normally includes filtration, ion exchange, adsorption and membrane process. The major disadvantage of the membrane process is the cost of periodic replacement. Thus, attention has been focused on investigate an alternative way on treating the effluents.s

Advanced oxidation process (AOP) is an alternative technique of destructing the harmful organic pollutants from wastewater through an oxidative breakdown initiated by a powerful oxidizing species such as hydroxyl radicals. Photodegradation is a type of advanced oxidation process which involve chemical transformation of a photodegradable molecule into smaller compounds $\left(\mathrm{CO}_{2}, \mathrm{H}_{2} \mathrm{O}\right.$ and degraded products) that are caused by the absorption of photons, particularly between the range of wavelengths that found in sunlight, such as infrared, visible light and ultraviolet light.

Titanium dioxide photocatalytic oxidation of organic compounds in wastewater has attracted a great deal of attention during the past decade. There are typically two types of reactor catalyst that have been used in degrading organic compound; a slurry and immobilized catalyst. A slurry type refers to $\mathrm{TiO}_{2}$ 
powder which is suspended in the water to be treated, while the immobilized catalyst is being referred to $\mathrm{TiO}_{2}$ powder attached to a substrate which is immersed in the water to be treated ${ }^{4}$. In comparison of both methods, the immobilized $\mathrm{TiO}_{2}$ has becoming more popular due to the complications of $\mathrm{TiO}_{2}$ suspension systems such as catalyst recovery stage involving microfiltration. Due to the small particle size of $\mathrm{TiO}_{2}$, this posttreatment step is necessary. However, this would be undesirable on industrial scale as this would add to the capital and operating costs of the treatment. To avoid this problem, the best solution would probably through the immobilization of $\mathrm{TiO}_{2}$ on a supporting material so that the photocatalyst can be re-used and the additional high cost of filtration treatment can be avoided.

The use of titanium dioxide as a catalyst for the photooxidation of organic compounds has received much interest because it has been proven to be efficient, biologically and chemically inert, inexpensive, resistant to photocorrosion and chemical corrosion, non toxic, highly photoactive, recyclable and has suitable band gap $\left(\mathrm{E}_{\mathrm{g}}=3.2 \mathrm{eV}\right)$. In this study, we report the efficiency of immobilized $\mathrm{TiO}_{2}$ in decolouring organic dyes for pollution prevention.

\section{EXPERIMENTAL}

The cationic dye, malachite green $(\mathrm{MG})$ oxalate $(\mathrm{CI}=$ 42000) was purchased from Sigma-Aldrich (M) Sdn. Bhd. and used as received without further purification. Synthetic dye solution of malachite green with the concentration of 1000 $\mathrm{mg} / \mathrm{L}$ was prepared as stock solution and subsequently diluted when necessary.

The $\mathrm{TiO}_{2}$ powder P-25 (mainly in anatase form, mean particle size of $30 \mathrm{~nm}$, BET surface area of $50 \mathrm{~m}^{2} / \mathrm{g}$ ) from Degussa (Frankfurt, Germany) was used as the photocatalyst in this study.

99.9\% methanol solution was purchased from MERCK.

Immobilization of $\mathrm{TiO}_{2}$ on glass plates: $\mathrm{TiO}_{2}$ suspension was prepared by using $1 \mathrm{~g}$ of $\mathrm{TiO}_{2}$ added to $20 \mathrm{~mL}$ of $99.9 \%$ methanol solution. The resulting mixture was stirred continuously until all the $\mathrm{TiO}_{2}$ powders were uniformly dispersed. The glass plate $\left(2.5^{\prime \prime} \times 1.0^{\prime \prime} \times 0.1^{\prime \prime}\right)$ was dipped into the mixture (considered as 1 time dip coating). The initial weight and final weight of glass plate were measured to calculate the amount of $\mathrm{TiO}_{2}$ coated.

Batch experiments: Irradiation experiments were carried out by stirring $1500 \mathrm{~mL}$ of $5 \mathrm{mg} / \mathrm{L}$ of malachite green dye solution (without changing its $\mathrm{pH}$ ) in a glass tank with 6 immobilized $\mathrm{TiO}_{2}$ glass plates. For each experimental run, the weight of immobilized $\mathrm{TiO}_{2}$ used was maintained at approximately $1.1 \mathrm{~g}$. Aeration was provided by bubbling air into the reaction solution by an air pump to ensure a constant supply of oxygen. At given intervals of irradiation, approximately $10 \mathrm{~mL}$ of the solution was withdrawn from the reservoir and the concentration of dye in the solution was determined using a Shimadzu 1700 PharmaSpec UV-VIS spectrophotometer. All measurements were made at the wavelength corresponding to maximum absorption; for malachite green, $\lambda_{\max }=$ $617 \mathrm{~nm}$.
Effect of initial dye concentration and contact time: The effect of initial dye concentration and contact time was investigated using dye concentrations of 5, 10, $25 \mathrm{mg} / \mathrm{L}$. The samples were withdrawn and analyzed for their dye concentrations at predetermined intervals, 5, 10, 15, 30, 60, 120, 180, 240, 300 and $360 \mathrm{~min}$.

Effect of number of dip-coating: The study on the effect of photocatalyst loading on the photodegradation efficiency was carried out by varying the number of repetitive $\mathrm{TiO}_{2}$ dip coatings, keeping the number of glass plates constant ( 6 glass plates of $\mathrm{TiO}_{2}$ ). The number of $\mathrm{TiO}_{2}$ dip coatings studied was 5, 10 and 15 times.

Effect of repetitive usage and recycle of dip coated $\mathrm{TiO}_{2}$ glass plates: To study the number of usage of the $\mathrm{TiO}_{2}$ glass plates, photodegradation experiments were repeated using the same glass plates. The recycle process was carried out by soaking the used $\mathrm{TiO}_{2}$ glass plates in distilled water and exposing them under sunlight for one day. After recycling, the $\mathrm{TiO}_{2}$ glass plates were reused in order to study the efficiency of the recycled $\mathrm{TiO}_{2}$ glass plates in the subsequent photodegradation process.

Effect of light source: The effect of light source was studied by using different light sources, namely UV lamp, white fluorescent and sunlight.

\section{RESULTS AND DISCUSSION}

Effect of initial dye concentration and contact time: The influence of initial dye concentration and contact time on percentage of malachite green removal is shown in Fig. 1. The removal of malachite green decreased from 100-88.47 and $83.51 \%$ for the initial concentrations of 5, 10 and $25 \mathrm{mg} / \mathrm{L}$, respectively. As the dye concentration increased, the large amount of adsorbed dye inhibited the reaction of dye molecules with photo-generated holes or hydroxyl radicals because there was no direct contact of $\mathrm{TiO}_{2}$ with the dye molecules. Increasing the dye concentration also caused the dye molecules to absorb light and the photons never reached $\mathrm{TiO}_{2}$ surface 5 . Similar trend was reported for the UV light induced photodegradation of malachite green on $\mathrm{TiO}_{2}$ nanoparticles. When refer to Beer-Lambert law, as the initial dye concentration increases, the path length of photons entering the solution decreases, resulting in lower photon adsorption on catalyst particles, thus resulted in lower percentage of dye removal ${ }^{6}$.

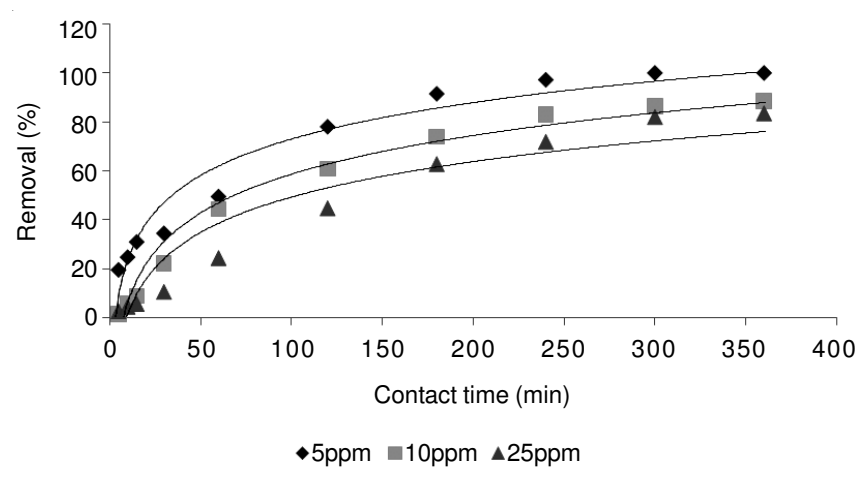

Fig. 1. Effect of initial concentration and contact time on photodegradation of malachite green 
Effect of numbers of dip-coating: The study of the dependence of the photocatalytic reaction rate on the concentration of $\mathrm{TiO}_{2}$ in the malachite green solution is important. From Fig. 2, it showed that the removal of malachite green increased from 92.15-94.28 and $98.43 \%$ for 5, 10 and 15 number of $\mathrm{TiO}_{2}$ dip-coatings, respectively. The total weight of $\mathrm{TiO}_{2}$ loaded on 5, 10 and 15 number of dip-coatings was $0.226,0.433$ and $0.690 \mathrm{~g}$, respectively. The amount of $\mathrm{TiO}_{2}$ coated on the glass plate is proportional to the number of dip coating; the increase in catalyst loading on the glass plates will increase the number of active sites. As a result, more $\mathrm{TiO}_{2}$ particles were excited by sunlight and more electron-hole pair was generated. These generated electron-hole pairs will react with water, hydroxide ion or oxygen to form hydroxyl radicals, which are powerful oxidizing species. With the generation of more hydroxyl radicals, a higher dye removal rate is therefore anticipated. Similar trend was reported for the photo-degradation of commercial dye, procion blue HERD from real textile wastewater using nanocatalysts ${ }^{7}$.

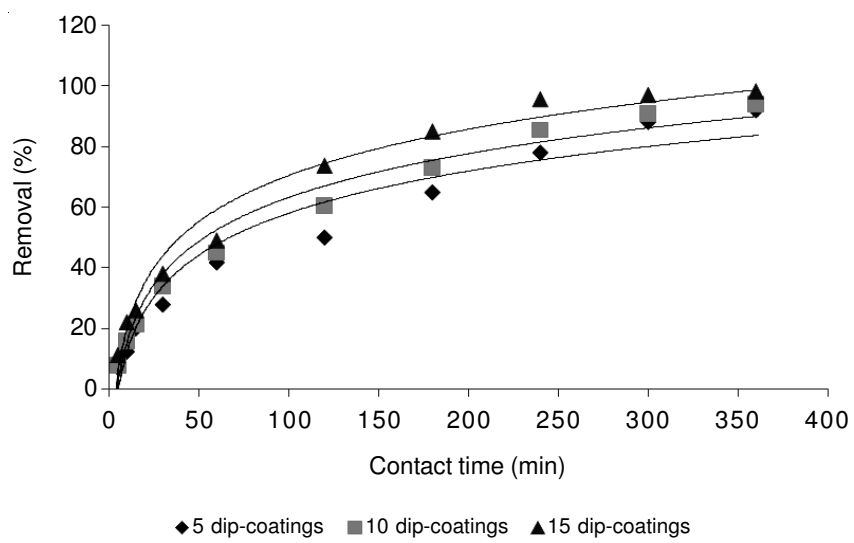

Fig. 2. Effect of number of $\mathrm{TiO}_{2}$ dip-coating on percentage removal of malachite green

Effect of light source: The incident light determines the photogenerated electron-hole pair concentration and the formation of hydroxyl radicals. In this study, various types of lamps were used as illumination source ranging from visible to near UV light which includes sunlight, UV lamp (100 W) and fluorescent lamp. The light source used is an indicator to evaluate the operating cost and the efficiency of photoreactor ${ }^{8}$. From Fig. 3, the percentage removal of malachite green was $100,46.1$ and 41.58 for sunlight, UV light and fluorescence light, respectively. The experimental results show that the removal efficiency of malachite green was higher using sunlight light than other light sources. Similar trend was reported for the photocatalytic degradation of basic and reactive dyes in both single and binary systems using immobilized $\mathrm{TiO}_{2}{ }^{9}$.

The generation of electron-hole pair is closely related to the light intensity ${ }^{9}$. Thus it is expected that sunlight or UV light with higher light intensity at wavelength range $<380 \mathrm{~nm}$ should be the most effective followed by fluorescent light and other artificial light with lower light intensity at the same wavelength. The results obtained are in accordance with this order.

Effect of repetitive usage and recycle of dip coated $\mathrm{TiO}_{2}$ glass plates: The regeneration of $\mathrm{TiO}_{2}$ photocatalyst is one of key steps to make this type of heterogeneous photocatalysis

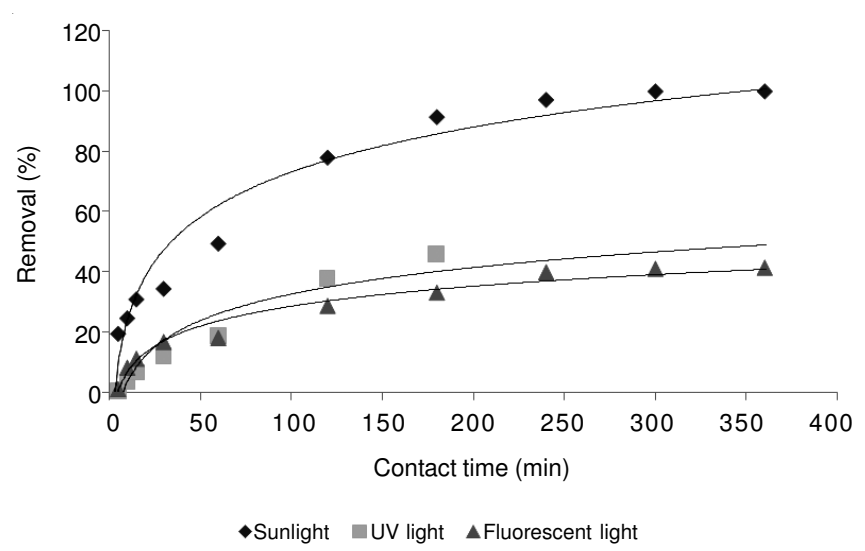

Fig. 3. Effect of light source on percentage removal of malachite green

technology applicable for practical usage. Thus, a study on the repetitive usage and recycle of dip coated $\mathrm{TiO}_{2}$ glass plates was carried out. The result showed that the percentage of colour removal decreases with increasing number of usage. The removal of malachite green under sunlight for each cycles were 99.04, 99.01, 97.41, 95.89, 91.70, 86.64, 74.73 and $63.35 \%$ for up to 8 cycles of repetitive usage, respectively.

From Fig. 4, the decrease in decolorization efficiency may be due to the non-eliglible adsorbed dye molecules on the $\mathrm{TiO}_{2}$ glass plates. These adsorbed dye molecules hindered the photocatalyst, $\mathrm{TiO}_{2}$ from being illuminated by the light source and thus hindered the formation of electron-hole pairs and retard the formation of beneficial radicals. This similar observation was also reported from the photocatalytic degradation of basic and reactive dyes in both single and binary systems using immobilized $\mathrm{TiO}_{2}{ }^{9}$. This indicated that the dye molecules are strongly adsorbed on the $\mathrm{TiO}_{2}$ glass plates and it cannot be removed by the recycling method applied.

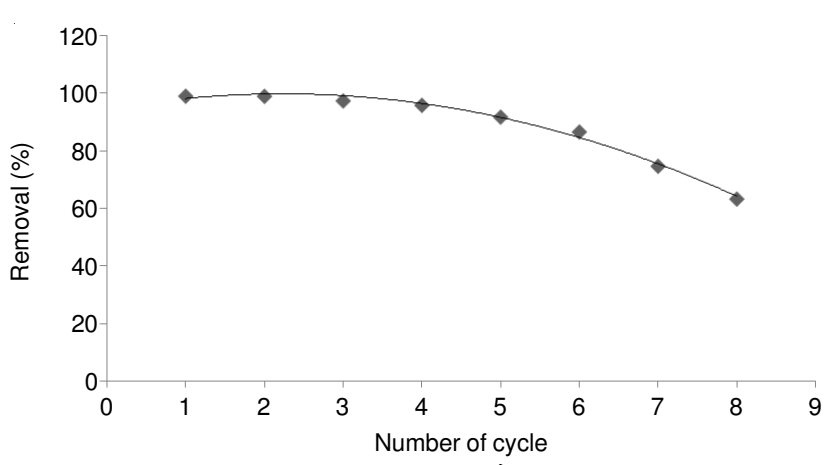

Fig. 4. Effect of repetitive usage and recycle of dip coated $\mathrm{TiO}_{2}$ on percentage removal of malachite green

Photodegradation kinetic study: A study of photodegradation kinetics can provide information about the mechanism of photodegradation which is important to maximize photodegradation efficiencies in removal of pollutants. The degradation of various organic contaminants over illuminated $\mathrm{TiO}_{2}$ has been reported to conform to the Langmuir- Hinshelwood (LH) kinetics model ${ }^{10}$. Assumptions for LH model have been described and suggested that ${ }^{11}$ : (1) Only one substrate can bind at each surface site. (2) At equilibrium the number of surface adsorption sites is fixed. (3) There is no interaction between adjacent adsorbed substrates. (4) The rate of surface adsorption 
of the substrate is greater than the rate of any subsequent chemical reactions. (5) The heat of adsorption by the substrate is identical for each site and is independent of surface coverage.

The first order model as expressed in eqn. 1 is generally used for photodegradation process of organic pollutants to obtain the rate constants,

$$
-\frac{\mathrm{dC}}{\mathrm{dt}}=\mathrm{kC}
$$

which after intergration gives

$$
\mathrm{C}=\mathrm{C}_{0} \exp (-\mathrm{kt})
$$

where $\mathrm{C}=$ concentration of the dye solution $(\mathrm{mg} / \mathrm{L})$ at time $\mathrm{t}$, $\mathrm{C}_{0}=$ initial concentration of the dye solution $(\mathrm{mg} / \mathrm{L}), \mathrm{k}=$ first order rate constant (1/min).

Alternatively the relationship can be expressed as:

$$
\ln \frac{\mathrm{C}}{\mathrm{C}_{0}}=-\mathrm{kt}
$$

where $\mathrm{C} / \mathrm{C}_{0}$ is the normalized malachite green concentration and $\mathrm{k}$ the apparent rate constant $(1 / \mathrm{min})$.

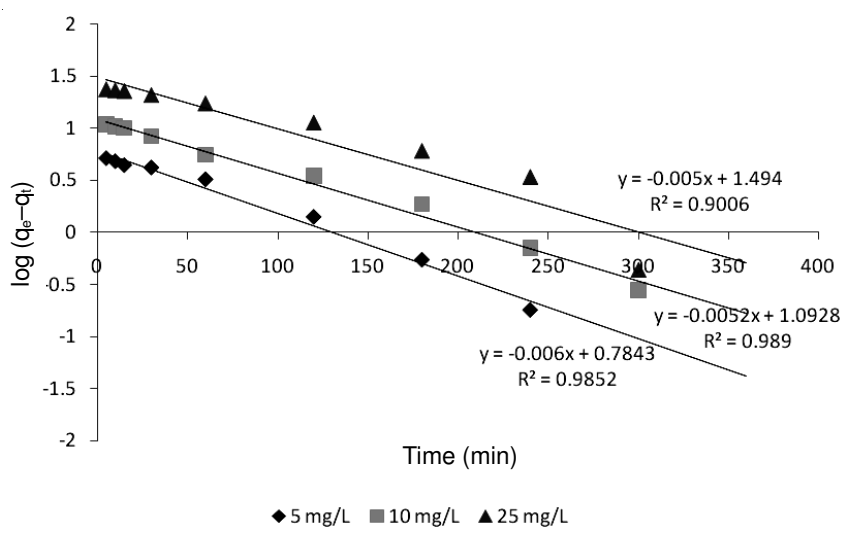

Fig. 5. Pseudo-first order for photodegradation of malachite green by $\mathrm{TiO}_{2}$

Plotting the data using the equation $\ln \left(\mathrm{C} / \mathrm{C}_{0}\right)$ versus time, a linear relationship is obtained in the photodegradation of malachite green, however the lines do not pass through the origin, indicating that most likely pseudo first-order kinetics was obeyed. As such, the experimental data were fitted into pseudo first-order kinetics equation:

$\log \left(\mathrm{q}_{\mathrm{e}}-\mathrm{q}_{\mathrm{t}}\right)=\log \mathrm{q}_{\mathrm{e}}-\mathrm{k}_{1} \mathrm{t} / 2.303$ (pseudo-first order equation ${ }^{12}$ ) where $\mathrm{q}_{\mathrm{e}}=$ the amount of dyes sorbed at equilibrium $(\mathrm{mg} / \mathrm{g})$, $\mathrm{q}_{\mathrm{t}}=$ the amount of dyes sorbed at time $\mathrm{t}(\mathrm{mg} / \mathrm{g}), \mathrm{k}_{1}=$ the rate constant of pseudo-first order sorption ( $1 / \mathrm{min})$. It was found that the application of pseudo-first provides a good correlation with the experimental data (Table-1). As depicted in Table-1, the rate constants in all the dye solutions decreased with increasing initial concentration. Again, this is related to the

\begin{tabular}{|c|c|c|c|c|}
\hline \multicolumn{5}{|c|}{$\begin{array}{c}\text { TABLE-1 } \\
\text { PSEUDO-FIRST ORDER KINETIC MODEL FOR } \\
\text { PHOTODEGRADATION OF MALACHITE GREEN }\end{array}$} \\
\hline \multirow{3}{*}{$\begin{array}{c}\text { Initial } \\
\text { concentration } \\
(\mathrm{mg} / \mathrm{L})\end{array}$} & \multicolumn{4}{|c|}{ Pseudo-first order } \\
\hline & \multirow{2}{*}{$\mathrm{k}_{1}\left(\min ^{-1}\right)$} & \multicolumn{2}{|c|}{$\mathrm{q}_{\mathrm{e}}(\mathrm{mg} / \mathrm{g})$} & \multirow{2}{*}{$\mathrm{R}^{2}$} \\
\hline & & Exp. & Calcd. & \\
\hline 5 & 0.014 & 6.09 & 6.38 & 0.985 \\
\hline 10 & 0.012 & 12.38 & 11.22 & 0.989 \\
\hline 25 & 0.011 & 31.19 & 24.44 & 0.901 \\
\hline
\end{tabular}
formation of hydroxyl radicals which are the critical species in the photodegradation process.

\section{Conclusion}

From this study, it is evident that the immobilized $\mathrm{TiO}_{2}$ is capable in removing malachite green under the illumination of sunlight. The results in this study indicated that the percentage removal of malachite green was influenced by initial dye concentration, contact time, numbers of dip-coating and light source. Under the illumination of three different light sources (sunlight, UV light and fluorescent light), sunlight displayed the highest percentage removal of malachite green. The percentage of dye removal decreased with increasing number of usages of immobilized $\mathrm{TiO}_{2}$. However, the immobilized $\mathrm{TiO}_{2}$ still displayed a good performance in the removal of malachite green and serves as an attractive yet economical approach to remove dye from aqueous environment.

\section{ACKNOWLEDGEMENTS}

The financial support by the International Foundation of Science, Stockholm, Sweden and the Organisation for the Prohibition of Chemical Weapons, The Hague, The Netherlands via grant No. W/4368-1 and research facilities from Universiti Tunku Abdul Rahman (UTAR) are gratefully acknowledged.

\section{REFERENCES}

1. Y. Chen, K. Wang and L. Lou, J. Photochem. Photobiol. A: Chem., 163, 281 (2004).

2. Z. Zainal, K.H. Lee, M.Z. Hussein, A.H. Abdullah and I.R. Hamadneh, J. Hazard. Mater., 164, 138 (2009).

3. M.A. Behnajady, N. Modirshahla, N. Daneshvar and M. Rabbani, J. Hazard. Mater., 140, 257 (2007).

4. L.L.P. Lim, R.J. Lynch and S.I. In, Appl. Catal. A, 365, 214 (2009).

5. J.H. Lee, W.S. Nam, M.S. Kang, G.Y. Han, K.J. Yoon, M.S. Kim, K.J. Ogino, S. Miyata and S.J. Choung, Appl. Catal. A, 244, 49 (2003).

6. C.C. Chen, C.S. Lu, Y.C. Chung and J.L. Jan, J. Hazard. Mater., 141, 520 (2007).

7. P. Bansai and D. Sud, Desalination, 267, 244 (2010).

8. Z. Zainal, K.H. Lee, M.Z. Hussein, Y.H. Taufiq-Yap, A.H. Abdullah and I. Ramli, J. Hazard. Mater., B125, 113 (2005).

9. S.T. Ong, C.K. Lee, Z. Zainal, P.S. Keng and S.T. Ha, J. Fundamental Sci., 5, 88 (2009).

10. I.K. Konstantinou, V.A. Sakkas and T.A. Albanis, Wat. Res., 36, 2733 (2002).

11. M.A. Fox and M.T. Dulay, J. Photochem. Photobiol. A: Chem., 98, 91 (1996).

12. S. Langergren and B.K. Svenska, Veternskapsakad Handlingar, 24, 1 (1898). 